\title{
Pelvic Insufficiency Fractures in Cervical Cancer After Radiation Therapy: A Meta-Analysis and Review
}

\author{
YOUN KYUNG CHUNG ${ }^{1 *}$, YOUNG-KYUN LEE ${ }^{2 *}$, \\ BYUNG-HO YOON ${ }^{3}$, DONG HOON SUH ${ }^{4}$ and KYUNG-HOI KOO ${ }^{2,5}$

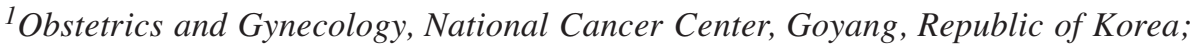 \\ ${ }^{2}$ Department of Orthopedic Surgery, Seoul National University Bundang Hospital, Seongnam, Republic of Korea; \\ ${ }^{3}$ Department of Orthopedic Surgery, Inje University College of Medicine, \\ Seoul Paik Hospital, Seoul, Republic of Korea; \\ ${ }^{4}$ Department of Obstetrics and Gynecology, \\ Seoul National University Bundang Hospital, Seongnam, Republic of Korea; \\ ${ }^{5}$ Department of Orthopedic Surgery, Seoul National University College of Medicine, Seoul, Republic of Korea
}

\begin{abstract}
Aim: The aim of the study was to estimate the prevalence of pelvic insufficiency fractures (PIFs) after radiation therapy $(R T)$ in patients with cervical cancer. Patients and Methods: A total of 3,633 patients from 15 cohort studies were included. Proportion meta-analysis was performed to estimate prevalence and subgroup analysis was performed according to imaging modalities for diagnosis of PIF. For continuous variables (age and length of follow-up), meta-regression analysis was performed. Results: Pooled prevalence estimate of PIF was $14 \%$ (95\% CI=10-19). Incidence of PIF was higher in studies that used MRI as a diagnostic tool $(17 \%, 95 \% C I=12-22)$ than non-MRI $(8 \%$, 95\% CI=2-14). In meta-regression, we found a significant association of prevalence of PIF with age $(p=0.021)$ but not with length of follow-up $(p=0.118)$. Conclusion: PIF after $R T$ in patients with cervical cancer is not rare. Physicians need to pay attention to PIFs, especially in patients with high-risk factors for osteoporotic fracture.
\end{abstract}

Cervical cancer is one of the fourth most common cancers in women. In 2020, an estimated 604,000 women were diagnosed with cervical cancer worldwide and about 342,000

This article is freely accessible online.

*These Authors contributed equally to this study.

Correspondence to: Dong Hoon Suh, Department of Obstetrics and Gynecology, Seoul National University Bundang Hospital, Gyeonggi-do, Republic of Korea. Tel: +82 317877263, e-mail: sdhwcj@naver.com

Key Words: Cervical cancer, survivoral care, osteoporosis, insufficiency fracture. women died from the disease (1). Pelvic radiotherapy (RT) is a well-established treatment in the management of cervical cancers either post-operatively or as a primary treatment (2). Major improvements in definitive RT have occurred during the past 15 to 20 years and survival rate improved $(3,4)$. Acute toxicity during pelvic RT is well recognized, but lateonset complications such as impaired bone health is still relatively under-diagnosed (5-7).

Pelvic insufficiency fracture (PIF) is a type of fracture which occurs within normal stress on bone, weakened by demineralization or decreased elastic resistance of bone matrix due to severe osteoporosis, previous RT, prolonged use of corticosteroids (8). Several studies investigated the incidence of RT-induced PIFs and have shown wide incidence rates ranging from $1.7 \%$ to $89 \%$ in patients undergoing treatment of gynecologic cancer (9-11). Due to this wide range of prevalence, the incidence of PIFs remains unclear and relevant systematic reviews and meta-analyses are rare.

Considering the increased number of cervical cancer survivors, it is important to determine whether and how many patients with cervical cancer are at increased risk of osteoporotic fracture after RT. The objective of this study was to estimate the incidence of RT-induced PIF in patients who received definitive or postoperative adjuvant RT for locally advanced cervical cancer.

\section{Patients and Methods}

Search protocol and selection of studies. This meta-analysis was conducted according to the updated guidelines of the Preferred Reporting Items for Systematic Review and Meta-Analysis Protocols (PRISMA-P) (6). Two researchers (blinded by the authors) independently searched MEDLINE (PubMed), EMBASE, and Cochrane Library databases in September 2018. Articles that met the selection criteria were included in the meta-analysis. We 
Table I. Characteristics of included individual studies that reported the prevalence of pelvic insufficiency fracture in patients treated with cervical cancer who underwent radiation therapy.

\begin{tabular}{|c|c|c|c|c|c|c|c|c|}
\hline \multirow[t]{2}{*}{ Study name } & \multirow[t]{2}{*}{ Study design } & \multirow[t]{2}{*}{ Period } & \multirow[t]{2}{*}{ Diagnosis } & \multicolumn{2}{|c|}{ Sample size } & \multirow{2}{*}{$\begin{array}{c}\text { RT dose } \\
\text { (gray, median) }\end{array}$} & \multirow{2}{*}{$\begin{array}{l}\text { Median age } \\
\text { (years) }\end{array}$} & \multirow{2}{*}{$\begin{array}{l}\mathrm{F} / \mathrm{U} \text { year } \\
\text { (median) }\end{array}$} \\
\hline & & & & Total & PIF & & & \\
\hline Huh et al. (10) & Retrospective & $1994-2000$ & Bone-scan or $\mathrm{CT}$ & 463 & 8 & $50.4-55.8$ & - & 3.2 \\
\hline Ogino et al. (11) & Retrospective & 1983-1998 & Bone-scan or CT & 335 & 57 & $45-50$ & 66 & 3.3 \\
\hline Ikushima et al. (12) & Retrospective & 1993-2004 & CT\&MRI & 158 & 18 & 50 & 64 & 3.6 \\
\hline Kwon et al. (14) & Retrospective & $1998-2005$ & MRI & 510 & 100 & 50.4 & 54.7 & 1.2 \\
\hline Schmeler et al. (18) & Retrospective & 2001-2006 & CT\&MRI & 300 & 29 & 45 & 47.4 & 1.7 \\
\hline Park et al. (16) & Retrospective & 2004-2009 & $\mathrm{PET} / \mathrm{CT}$ or MRI & 235 & 16 & 55 & 55 & 2 \\
\hline Uezono et al. (21) & Retrospective & 2003-2009 & CT\&MRI & 99 & 33 & 50.4 & 68 & 1.8 \\
\hline Tokumaru et al. (20) & Longitudinal prospective & 2004-2007 & CT\&MRI & 59 & 21 & 50 & 73 & 2 \\
\hline Shih et al. (19) & Retrospective & $2000-2008$ & MRI & 222 & 11 & 50.4 & 57 & 3.9 \\
\hline Ioffe et al. (13) & Case-control & 1998-2009 & $\mathrm{PET} / \mathrm{CT}$ & 166 & 12 & $45-50$ & 50 & 4 \\
\hline Mehmood et al. (15) & Retrospective & $2007-2008$ & MRI & 148 & 33 & $40-45$ & 60 & - \\
\hline Ramlov et al. (17) & Longitudinal prospective & 2008-2014 & MRI & 101 & 20 & $50-60$ & 50 & 2.1 \\
\hline Yamamoto et al. (22) & Retrospective & $2003-2012$ & CT\&MRI & 533 & 84 & $50-50.4$ & 57.8 & 4.1 \\
\hline Salcedo et al. (8) & Longitudinal prospective & $2008-2015$ & - & 239 & 37 & NA & 51 & 3 \\
\hline Weidenbächer et al. (5) & Longitudinal prospective & 2013-2017 & MRI & 65 & 6 & 50.4 & - & - \\
\hline
\end{tabular}

CT, Computed tomography; F/U, follow-up; MRI, magnetic resonance imaging; NA, not available; PET, positron emission tomography; PIF, pelvic insufficiency fracture; RT, radiation therapy.

attempted to obtain complete data for the analysis by contacting the authors of articles with insufficient or missing data.

Two (blinded by authors) of the authors reviewed the retrieved full manuscripts to determine whether PIF after RT had been evaluated in the full manuscript. We included single-cohort studies that investigated the medical records of patients with cervical cancer who underwent RT. Exclusion criteria were as follows: (1) the study included endometrial or ovarian cancers; (2) the study used registry data that could influence the overall result due to large weight; (3) too small sample size ( $<20$ patients); (4) the article was a review, case report, or basic science study.

Outcome measures and data extraction. For every eligible study, the following data were extracted and entered into a spreadsheet by two reviewers independently: the family name of the first author, year of publication, country, patient age/body mass index, number of patients treated with cervical cancer, total amount of RT, diagnostic median length of follow-up, assessment tool; magnetic resonance image (MRI), computed tomography (CT), bone-scan.

Quality assessment and publication bias. Two of the authors (blinded by the authors) independently evaluated the quality of all studies, using the Newcastle-Ottawa Scales. This tool comprises three parameters: selection, comparability, and outcome. Each parameter consists of subcategorized items; selection has a maximum of four stars, comparability has a maximum of two stars, and exposure or outcome has a maximum of three stars. We assessed the presence of publication bias using Begg's funnel plot and Egger's test.

Statistical analysis. A proportion meta-analysis of the data from all relevant studies that reported the incidence of PIF. For the test of heterogeneity, we used Higgins I2 statistics, and there was significant heterogeneity $(p<0.001, \mathrm{I} 2=95.08 \%)$. Thus, we analyzed the data by using a random-effect model. We also performed subgroup by imaging modalities for a diagnosis (MRI scan vs. others). Meta-regression was used to evaluate the association between study results and continuous moderators (patient age and length of follow-up). All analyses were performed using STATA software (version 14.0; Stata Corporation, College Station, TX, USA). This study was exempted from institutional review board review since it did not involve any human subjects.

\section{Results}

Description of included studies. The primary search of the databases yielded 546 records. After duplicates were removed, 413 articles were screened according to title and abstract. As a result, 29 full-text articles were selected and reviewed for eligibility. Finally, there were 3,633 patients included from the 15 studies in the systematic review (Table I and Figure 1) (5, 8, 10-22).

Incidence of pelvic insufficiency fracture and subgroup analysis. The pooled prevalence estimate was $14 \%[95 \%$ confidence interval $(\mathrm{CI})=10-19]$. The incidence of PIF was higher in MRI $(17 \%$; $95 \% \mathrm{CI}=12-22)$ than in Non-MRI 1.90 (8\%; 95\% CI=2-14, $<<0.001$ ) (Figure 2). In the metaregression, we found a significant association between prevalence of PIF and patient age (Figure 3A), but not in the length of follow-up (Figure 3B).

Quality assessment and publication bias. In terms of the methodological quality, the mean value of the awarded stars 


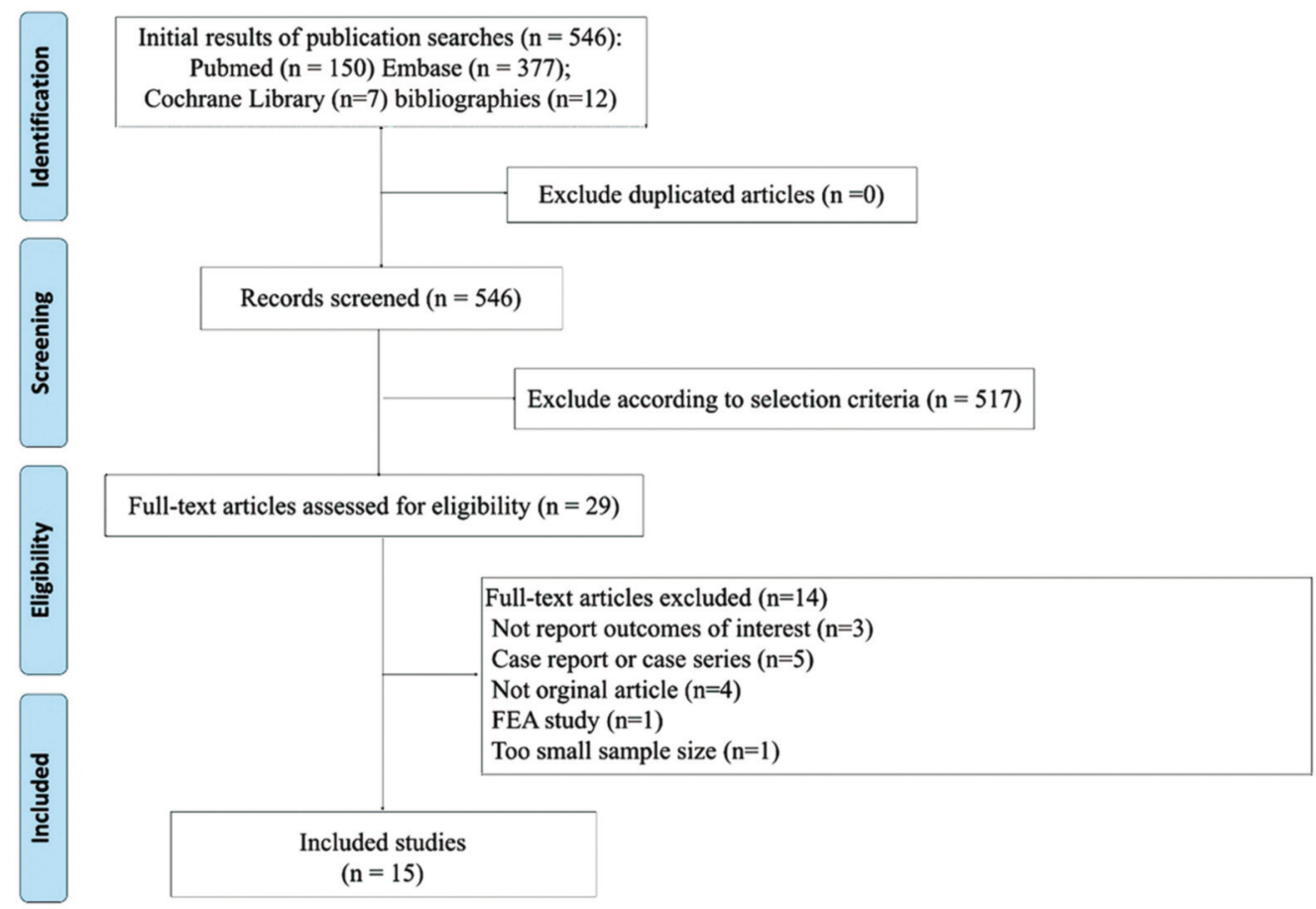

Figure 1. PRISMA flow diagram detailing the process of relevant clinical study selection.

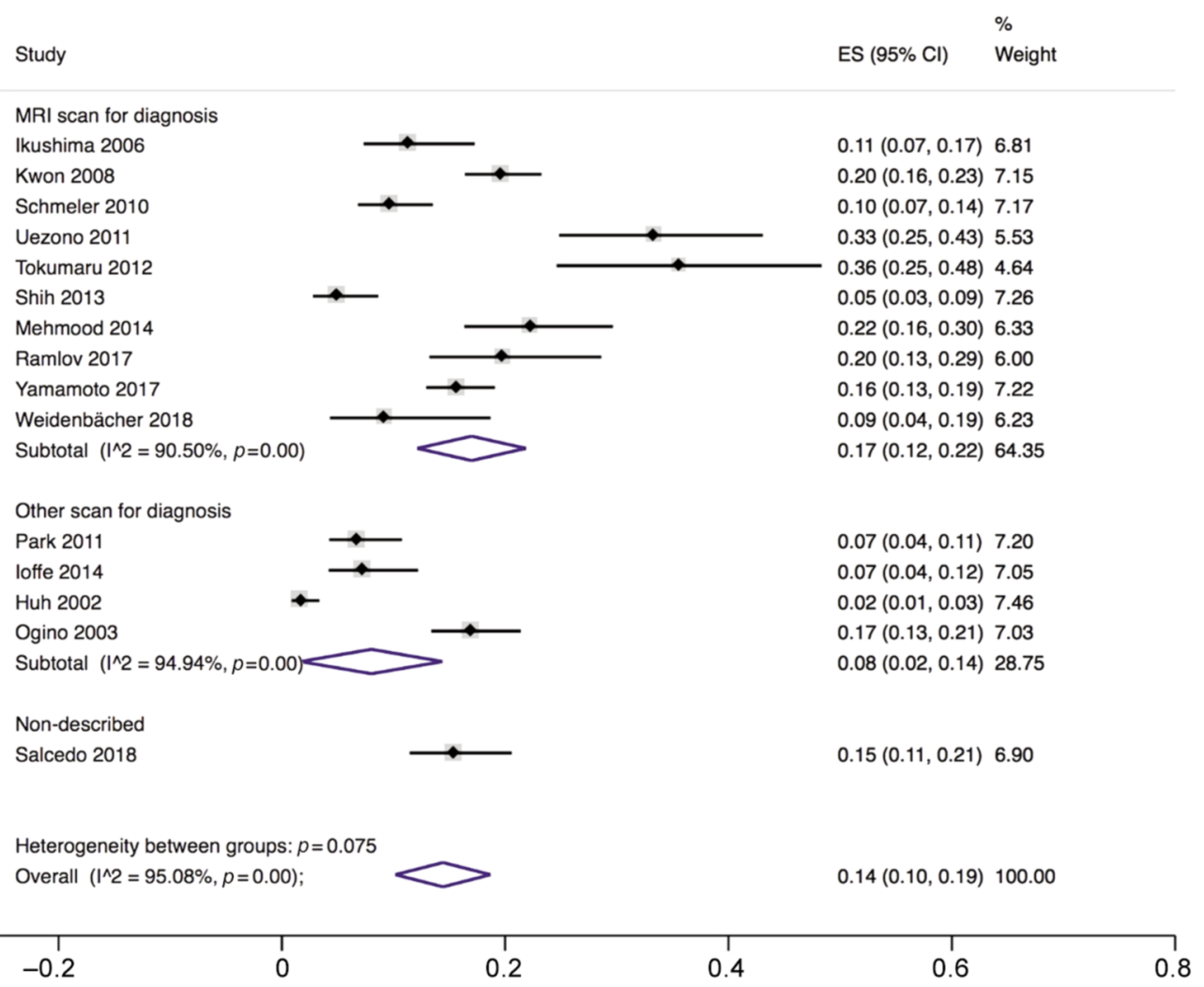

Figure 2. Forest plots show correlated proportions. (A) The prevalence of pelvic insufficiency fracture in studies used MRI for the diagnosis. (B) The prevalence of pelvic insufficiency fracture in studies did not use MRI for the diagnosis. 

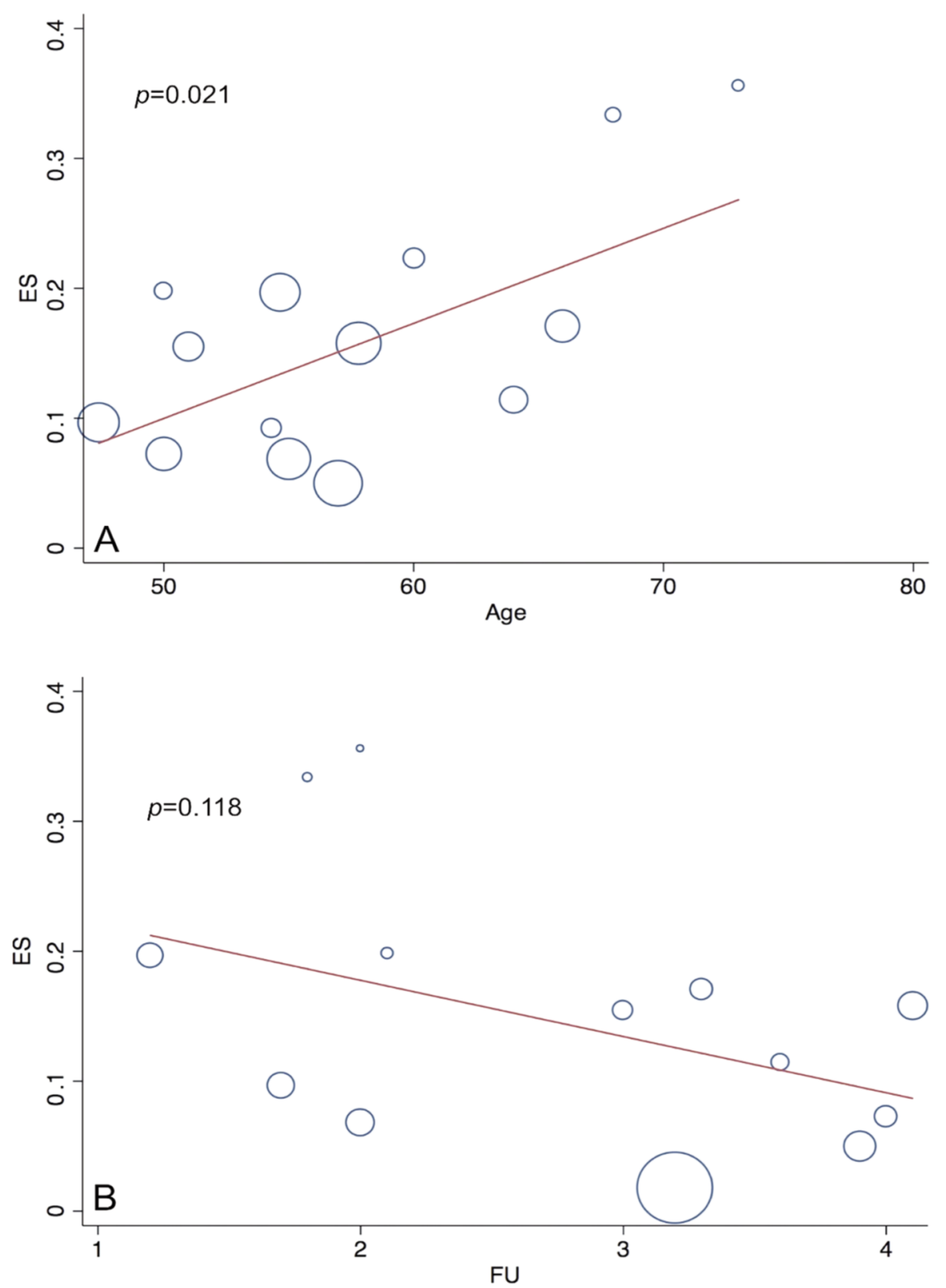

Figure 3. Meta-regression plot between the prevalence of pelvic insufficiency fracture and continuous variables from each study. (A) The median patient age of the study. (B) the median length of follow-up. ES, Effect size; FU, follow-up.

was 6.2 (2 studies had 5 stars, 8 studies had 6 stars, 5 studies had 7 stars; Table II). The Begg's funnel plot seems to be asymmetrical, but the $p$-value for bias was not significant (Figure 4).

\section{Discussion}

PIFs are a type of stress fractures that result from physiological stress applied to osteoporotic bones. Our meta- analysis found that the estimated prevalence of PIF is $14 \%$ and is much higher in the general population. In the United States, PIFs are estimated to affect approximately $2 \%$ female patients aged $>55$ years (23). The present study also revealed that studies which included MRI scan show a higher incidence of PIF than that of other modalities. The frequency of PIFs shows a wide range of incidence due to a variety of strategies for assessment of PIFs $(7,17,24)$, because PIFs are easily missed or underdiagnosed by clinical physicians 


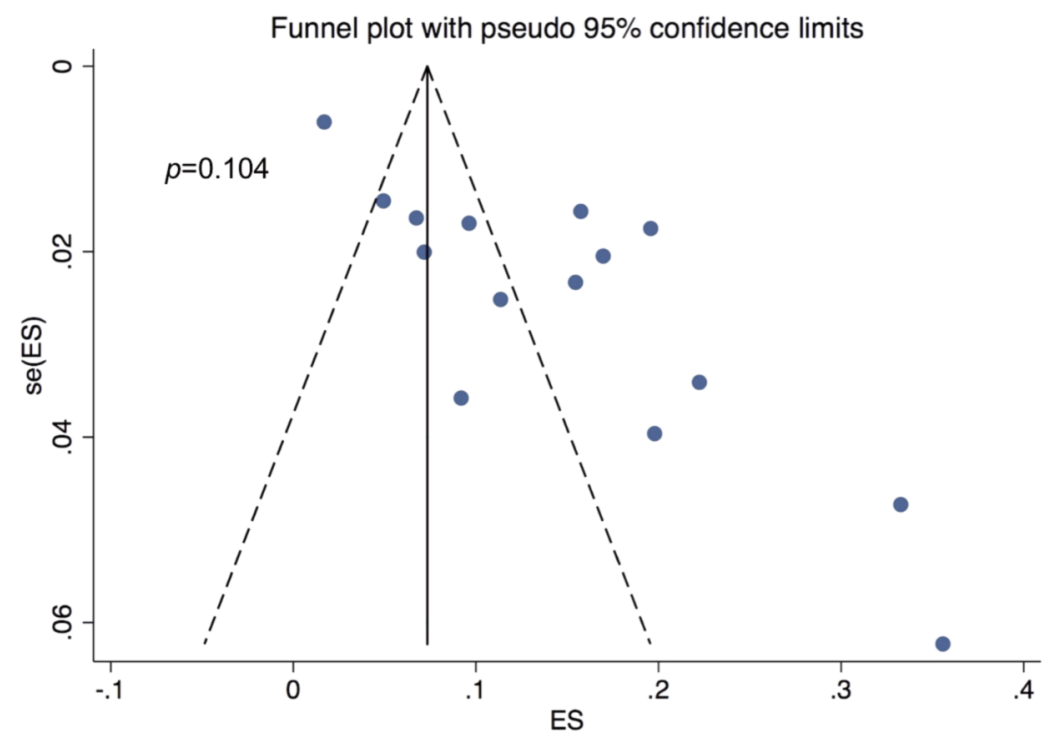

Figure 4. Begg's funnel plot and p-value by Egger's test. ES, Effect size; se, standard error.

(25). The overall sensitivity of MRI is more sensitive to the detection of PIF than CT scan (26). Bone scan still remains one of the most sensitive examinations in detection of PIFs, but it is not easy to differentiate between benign and malignant bone lesions with planar bone scan alone (27). Recently, pelvic MRI was routinely used to evaluate recurrence or resolution of tumor lesions, so clinical physicians pay more attention to PIFs in addition to their oncological follow-up.

Postmenopausal state or patients aged $>50$ has been known to be associated with the post-RT PIF in several previous studies $(17,21,22)$. In meta-regression analysis, median age of study is associated with a high prevalence of PIF, consistent with the finding that the most important risk factor for PIF is osteoporosis. Thus, it is important to evaluate bone mineral density providing relevant counseling before RT in postmenopausal patients with cervical cancer. However, drugs or guidelines recommended for the prevention and treatment of PIF induced by RT have not yet been determined. There is a concern that bisphosphonate suppresses bone turnover and has an antiangiogenic effect similar to that of RT, so it can lead to pathological fractures (28-30).

Our study showed no significant association between the length of follow-up and the incidence of PIF. Many previous studies showed that most PIFs occurred within 1 year which was in accordance with our results $(13,20,21)$. Osteoporosis may be exacerbated by a previous RT or altered biomechanical properties after RT can increase susceptibility to fracture $(31,32)$. Therefore, managing strategies for this condition should be focused, especially within one year of RT (18).
Table II. Methodological quality assessment of included studies measured by Newcastle-Ottawa scale.

\begin{tabular}{lcccc}
\hline Study name & Selection & Comparability & $\begin{array}{c}\text { Exposure } \\
\text { or outcome }\end{array}$ & Total \\
\hline Huh et al. $(10)$ & 3 & 1 & 3 & 7 \\
Ogino et al. $(11)$ & 3 & 1 & 3 & 7 \\
Ikushima et al. $(12)$ & 2 & 1 & 3 & 6 \\
Kwon et al. $(14)$ & 2 & 1 & 3 & 6 \\
Schmeler et al. $(18)$ & 2 & 1 & 2 & 5 \\
Park et al. $(16)$ & 3 & 1 & 2 & 6 \\
Uezono et al. $(21)$ & 3 & 1 & 2 & 6 \\
Tokumaru et al. $(20)$ & 3 & 1 & 3 & 7 \\
Shih et al. $(19)$ & 3 & 1 & 2 & 6 \\
Ioffe et al. $(13)$ & 2 & 1 & 2 & 5 \\
Mehmood et al. $(15)$ & 2 & 1 & 3 & 6 \\
Ramlov et al. $(17)$ & 3 & 1 & 3 & 7 \\
Yamamoto et al. $(22)$ & 3 & 1 & 2 & 6 \\
Salcedo et al. (8) & 3 & 1 & 3 & 7 \\
Weidenbächer et al. (5) & 3 & 1 & 2 & 6
\end{tabular}

To the best of our knowledge, this is the first metaanalysis estimating the prevalence of PIF in patients who received definitive or postoperative adjuvant RT for locally advanced cervical cancer. However, we note certain weaknesses in our study. Firstly, there was heterogeneity of strategy to detect PIF among the included studies. Heterogeneities in the enrollment time, timing of follow-up and different frequency of scans were also a limitation of the review. Secondly, this meta-analysis did not include control group, so we could not calculate the risk of fracture. Due to 
a lack of concern about osteoporosis or osteoporotic fracture in past decades, only a very few rigorously performed trials were executed, until recently. Lastly, many of the relationships between PIF and various risk factors were not appropriately evaluated due to lack of the information and low level of evidence of included studies.

\section{Conclusion}

In conclusion, we identified estimated prevalence of PIF after RT in patients with cervical cancer. Patients who have risk factors of osteoporosis should undergo early counseling and surveillance in addition to their oncological follow-up. Future active interventions, such as guideline including nutritional or pharmacological treatment for bone health from an early stage of treatment, are necessary for women with patients with cervical cancer who undergo RT.

\section{Conflicts of Interest}

The Authors declare no conflicts of interest.

\section{Authors' Contributions}

Conceptualization: C.Y.K., K.K., L.Y.; Methodology: C.Y.K., L.Y., Y.B.; Validation: L.Y., Y.B.; Formal analysis and investigation: C.Y.K., L.Y., Y.B.; Writing - original draft preparation: C.Y.K., Y.B.; Writing-review and editing: C.Y.K., K.K., L.Y., S.D.H., Y.B., Funding acquisition: K.K., L.Y.; Supervision: K.K., L.Y., S.D.H.

\section{Acknowledgements}

This work was supported by a grant of the Korea Health Technology R\&D Project through the Korea Health Industry Development Institute (KHIDI), funded by the Ministry of Health \& Welfare, Republic of Korea (grant number: HI18C0284).

\section{References}

1 Cancer fact sheets: Cervix uteri. Geneva, World Health Organization: Internationanl Agency for Research on Cancer, 2020. Available at: https://gco.iarc.fr/today/data/factsheets/ cancers/23-Cervix-uteri-fact-sheet.pdf [Last accessed on 1st January 2021]

2 Klaitong C, Meannuch E, Kaewbunperm U, Klaiphibule P and Sinthusek T: Radiotherapy at pelvis region in menopausal cervix cancer induce osteopenia/osteoporosis. Radiother Oncol 127: S819-S820, 2018. DOI: 10.1016/S0167-8140(18) 31821-8

3 Wu SG, Zhang WW, He ZY, Sun JY, Wang Y and Zhou J: Comparison of survival outcomes between radical hysterectomy and definitive radiochemotherapy in stage ib1 and iia 1 cervical cancer. Cancer Manag Res 9: 813-819, 2017. PMID: 29270030. DOI: $10.2147 / C M A R . S 145926$

4 Small W, Jr. and Kachnic L: Postradiotherapy pelvic fractures: Cause for concern or opportunity for future research? JAMA
294(20): 2635-2637, 2005. PMID: 16304079. DOI: 10.1001/ jama.294.20.2635

5 Weidenbächer B, Borm KJ, Oechsner M, Schiller K, Kampfer S, Alexander F, Combs SE and Duma MN: Pelvic fractures after radiotherapy for cervical cancer. Strahlenther Onkol 194(Suppl 1): 134, 2018. PMID: 29777265. DOI: 10.1007/s00066-018-1301-7

6 Maduro JH, Pras E, Willemse PH and de Vries EG: Acute and long-term toxicity following radiotherapy alone or in combination with chemotherapy for locally advanced cervical cancer. Cancer Treat Rev 29(6): 471-488, 2003. PMID: 14585258. DOI: 10.1016/s0305-7372(03)00117-8

7 Baxter NN, Habermann EB, Tepper JE, Durham SB and Virnig BA: Risk of pelvic fractures in older women following pelvic irradiation. JAMA 294(20): 2587-2593, 2005. PMID: 16304072. DOI: 10.1001/jama.294.20.2587

8 Salcedo PM, Sood A, Jhingran A, Eifel P, Klopp A, Iyer R, Felllman B, Jimenez C and Schmeler K: Pelvic fractures and changes in bone mineral density following pelvic radiotherapy for cervical, endometrial or vaginal cancer. Int J Gynecol Cancer 28(S2 Suppl 2): 44, 2018. PMID: 30212387. DOI: 10.1136/ 00009577-201809002-00001

9 Blomlie V, Rofstad EK, Talle K, Sundfor K, Winderen M and Lien $\mathrm{HH}$ : Incidence of radiation-induced insufficiency fractures of the female pelvis: Evaluation with mr imaging. AJR Am J Roentgenol 167(5): 1205-1210, 1996. PMID: 8911181. DOI: 10.2214/ajr.167.5.8911181

10 Huh SJ, Kim B, Kang MK, Lee JE, Lim DH, Park W, Shin SS and Ahn YC: Pelvic insufficiency fracture after pelvic irradiation in uterine cervix cancer. Gynecol Oncol 86(3): 264-268, 2002. PMID: 12217746. DOI: 10.1006/gyno.2002.6756

11 Ogino I, Okamoto N, Ono Y, Kitamura T and Nakayama H: Pelvic insufficiency fractures in postmenopausal woman with advanced cervical cancer treated by radiotherapy. Radiother Oncol 68(1): 61-67, 2003. PMID: 12885453. DOI: 10.1016/ s0167-8140(03)00128-2

12 Ikushima H, Osaki K, Furutani S, Yamashita K, Kishida Y, Kudoh T and Nishitani H: Pelvic bone complications following radiation therapy of gynecologic malignancies: Clinical evaluation of radiation-induced pelvic insufficiency fractures. Gynecol Oncol 103(3): 1100-1104, 2006. PMID: 16919711. DOI: $10.1016 /$ j.ygyno.2006.06.038

13 Ioffe YJ, Hillen TJ, Zhou G, Schwarz JK, Massad LS, Powell MA, Hagemann AR, Mutch DG and Thaker PH: Postradiation damage to the pelvic girdle in cervical cancer patients: Is intensity-modulated radiation therapy safer than conventional radiation? Int J Gynecol Cancer 24(4): 806-812, 2014. PMID: 24670967. DOI: 10.1097/IGC.0000000000000117

14 Kwon JW, Huh SJ, Yoon YC, Choi SH, Jung JY, Oh D and Choe BK: Pelvic bone complications after radiation therapy of uterine cervical cancer: Evaluation with mri. AJR Am J Roentgenol 191(4): 987-994, 2008. PMID: 18806132. DOI: 10.2214/ AJR.07.3634

15 Mehmood Q, Beardwood M, Swindell R, Greenhalgh S, Wareham T, Barraclough L, Livsey $\mathrm{J}$ and Davidson SE: Insufficiency fractures in patients treated with pelvic radiotherapy and chemotherapy for uterine and cervical cancer. Eur J Cancer Care (Engl) 23(1): 43-50, 2014. PMID: 23889218. DOI: $10.1111 /$ ecc.12105

16 Park SH, Kim JC, Lee JE and Park IK: Pelvic insufficiency fracture after radiotherapy in patients with cervical cancer in the 
era of pet/ct. Radiat Oncol J 29(4): 269-276, 2011. PMID: 22984680. DOI: 10.3857/roj.2011.29.4.269

17 Ramlov A, Pedersen EM, Rohl L, Worm E, Fokdal L, Lindegaard JC and Tanderup K: Risk factors for pelvic insufficiency fractures in locally advanced cervical cancer following intensity modulated radiation therapy. Int J Radiat Oncol Biol Phys 97(5): 1032-1039, 2017. PMID: 28332986. DOI: $10.1016 /$ j.ijrobp.2017.01.026

18 Schmeler KM, Jhingran A, Iyer RB, Sun CC, Eifel PJ, Soliman PT, Ramirez PT, Frumovitz M, Bodurka DC and Sood AK: Pelvic fractures after radiotherapy for cervical cancer: Implications for survivors. Cancer 116(3): 625-630, 2010. PMID: 20052724. DOI: 10.1002/cncr.24811

19 Shih KK, Folkert MR, Kollmeier MA, Abu-Rustum NR, Sonoda Y, Leitao MM, Jr., Barakat RR and Alektiar KM: Pelvic insufficiency fractures in patients with cervical and endometrial cancer treated with postoperative pelvic radiation. Gynecol Oncol 128(3): 540-543, 2013. PMID: 23262211. DOI: 10.1016/ j.ygyno.2012.12.021

20 Tokumaru S, Toita T, Oguchi M, Ohno T, Kato S, Niibe Y, Kazumoto T, Kodaira T, Kataoka M, Shikama N, Kenjo M, Yamauchi C, Suzuki O, Sakurai H, Teshima T, Kagami Y, Nakano T, Hiraoka M, Mitsuhashi N and Kudo S: Insufficiency fractures after pelvic radiation therapy for uterine cervical cancer: An analysis of subjects in a prospective multiinstitutional trial, and cooperative study of the japan radiation oncology group (jarog) and japanese radiation oncology study group (jrosg). Int J Radiat Oncol Biol Phys 84(2): e195-200, 2012. PMID: 22583605. DOI: 10.1016/j.ijrobp.2012.03.042

21 Uezono H, Tsujino K, Moriki K, Matsumoto Y, Nagano F, Ota Y, Sugimura K, Sasaki R and Soejima T: Bone injury after definitive radiotherapy for uterine cervical cancer: Retrospective analysis of risk factors. Int J Radiat Oncol Biol Phys 81(2): S461, 2011. DOI: 10.1016/j.ijrobp.2011.06.988

22 Yamamoto K, Nagao S, Suzuki K, Kogiku A, Senda T, Yano H, Kitai M, Shiozaki T, Matsuoka K and Yamaguchi S: Pelvic fractures after definitive and postoperative radiotherapy for cervical cancer: A retrospective analysis of risk factors. Gynecol Oncol 147(3): 585-588, 2017. PMID: 29055558. DOI: 10.1016/ j.ygyno.2017.09.035

23 Nih Consensus Development Panel on Osteoporosis Prevention D and Therapy: Osteoporosis prevention, diagnosis, and therapy. JAMA 285(6): 785-795, 2001. PMID: 11176917. DOI: 10.1001/ jama.285.6.785

24 Hile E and Harrington S: Fracture risk in gynecologic cancer survivors: Research round-up. Rehabil Oncol 34(1): 48, 2016. DOI: 10.1097/01.REO.0000475665.83280.ca
25 Kao FC, Hsu YC, Liu PH, Yeh LR, Wang JT and Tu YK: Osteoporotic sacral insufficiency fracture: An easily neglected disease in elderly patients. Medicine (Baltimore) 96(51): e9100, 2017. PMID: 29390438. DOI: 10.1097/MD .0000000000009100.

26 Kim YY, Chung BM and Kim WT: Lumbar spine mri versus non-lumbar imaging modalities in the diagnosis of sacral insufficiency fracture: A retrospective observational study. BMC Musculoskelet Disord 19(1): 257, 2018. PMID: 30045747. DOI: 10.1186/s12891-018-2189-1

27 Zhang L, He Q, Jiang M, Zhang B, Zhong X and Zhang R: Diagnosis of insufficiency fracture after radiotherapy in patients with cervical cancer: Contribution of technetium tc $99 \mathrm{~m}$-labeled methylene diphosphonate single-photon emission computed tomography/computed tomography. Int J Gynecol Cancer 28(7): 1369-1376, 2018. PMID: 30095704. DOI: 10.1097/IGC. 0000000000001337

28 Oh BH, Heo YM, Yi JW, Kim TG and Lee JS: Atypical fracture of the proximal shaft of the ulna associated with prolonged bisphosphonate therapy. Clin Orthop Surg 10(3): 389-392, 2018. PMID: 30174818. DOI: 10.4055/cios.2018.10.3.389

29 Kwak SJ, Cho YJ, Jung GY, Lee JH, Chun YS and Rhyu KH: Acetabular insufficiency fracture following prolonged alendronate use and the failure of total hip arthroplasty in "frozen" bone: Two cases report. Hip Pelvis 29(4): 286-290, 2017. PMID: 29250504. DOI: 10.5371/hp.2017.29.4.286

30 Kang H, Park YC and Yang KH: Paget's disease: Skeletal manifestations and effect of bisphosphonates. J Bone Metab 24(2): 97-103, 2017. PMID: 28642853. DOI: $10.11005 / \mathrm{jbm}$. 2017.24.2.97

31 Franklin G: Abstracts of Oral and Poster Presentations 20th Annual Meeting of the American College of Radiation Oncology February 25-27, 2010 Orlando, Florida. Am J Clin Oncol 33(2): 205-206, 2010. DOI: 10.1097/01.coc.0000370565.44945.bc

32 Bliss P, Parsons CA and Blake PR: Incidence and possible aetiological factors in the development of pelvic insufficiency fractures following radical radiotherapy. Br J Radiol 69(822): 548-554, 1996. PMID: 8757658. DOI: 10.1259/0007-1285-69$822-548$
Received October 6, 2020

Revised January 2, 2021

Accepted January 12, 2021 